\title{
Impacts Of Environment On Building Construction Projects On Woliata Sodo Town
}

\author{
Wudnesh Honja Angelo ${ }^{\mathrm{a}}$ \\ ${ }^{a}$ Lecturer, department of civil Engineering, Wolaita Sodo University, Ethiopia. \\ E-mail: wudehonja@yahoo.com
}

\begin{abstract}
The environmental impacts have become a series of problems in today's construction environments. Environmental conditions can have an adverse impact on the duration, cost, and quality of construction activities. This study is conducted to describe and point out the impact of the environment on building construction projects in sodo town. The contractor can estimate the Productivity loss due to the impact of environment on construction activity can be either partial or complete: partial loss is generally attributed to reduced labor productivity and work stoppage which interrupt those activities. This study organized by using questioners. The research basically focused on identifying and quantifying different environmental impacts that can affect the construction progresses. As the research result the escalation of construction material price, the availability of construction materials around the area and the involvement of different construction parties and the climatic condition of the environments are the main findings that we have got from our analysis. Generally, this research guides to meet future demands for sustainable environmental development, economic development, expansion of different construction infrastructure for sodo town. Many contractors found in this area fall over different environmental challenges. So to overcome these problems, are some requirements expected from different parties. To minimize those environmental impacts the construction parties should make a detail feasible study about the overall environmental conditions of sodo town before they decided to start up any construction works.
\end{abstract}

Key words: Building, Construction, Challenges, Environment, Environmental, Impact

\section{INTRODUCTION}

Construction is an important sector that contributes greatly to the economic growth of a nation. The Construction Industry is an investment-led sector where government shows high interest. Government contracts with Construction Industry to develop infrastructure related to health, transport as well as education sector. For the prosperity of any nation, Well-constructed infrastructure creates a healthy environment to work in, thereby increasing productivity and flexibility of the labor force.Construction is not an environmentally friendly process by nature. The cumulative environmental impacts of construction processes have been increasing in the world due to a large number of ongoing construction projects. Most of these impacts are related to the operation and maintenance phases of a building. A recent study EPA, 2009 shows that construction is the third largest industry sector in terms of contributions to greenhouse gas emissions

Effects of the Environment on the Project are associated with risks of natural hazards and influences of nature on the Project. Typically, potential effects of the environment on any project are a function of project or infrastructure design in the context of its receiving environment, and ultimately how the project is affected by nature. These effects may arise from physical conditions, land forms, and site characteristics or other attributes of the environment which may act on the project such that the project components, schedule, and/or costs could be substantively and adversely changed. In general, environmental conditions that can affect Construction of the Project, infrastructure, or operational performance will be communicated to the Design Team and addressed through engineering design and industry standards. Good engineering design involves the consideration of environmental effects and loadings or stresses.From the environment on a project. The planning and engineering design for this Project are no exception (Elis's Salleken, Environment and construction., 2003).

Equipment and materials that are able to withstand severe weather and other influences will be used. Environmental stressors, such as those that could arise as a result of climate change, severe weather, or other factors (e.g., natural events, fires), would more than adequately be addressed by good engineering design, materials selection, best practices, and engineering foresight. As will be demonstrated, while there is potential for natural forces to affect the Project, it is not likely to have a substantive effect on Construction or Operation due to planned mitigation and design. 
The construction projects are affected to some degree by adverse environmental factors. Construction projects in general are executed in different environment and therefore are affected by different environmental conditions. Environmental impact was one of the main factors causing delay and cost overruns on construction projects considerable number of construction activities are sensitive to environmental factors. (Rony, 2001). The impact of environment on construction project can be in the form of reduced labor productivity and work cross. Reduced labor productivity is generally attributed reduced human performance due to heat or cold stress resulting from combined effect of temperature, humidity and wind velocity. Environment related work stoppage is attributed either to the inability of construction personal to work under sever environmental condition of heavy rain, harsh sun and gusting winds or simply to compliance with safety regulations in such adverse environmental impact.

The Contractors uses several methods to perform environmental impact analysis. While these methods attain some degree of success, it is not unusual construction projects to experience contract time growth due to severe environmental impact. An improved and uniform approach to severe environmental impact analysis on construction projects will minimize this type of delay (Al-hammed, 1997). The proposed method helps to estimate and evaluate the impact of severe environmental factor on construction projects in sodo by analyzing historical environmental data along with severe environmental impacts of specific construction activities as the basis for analysis.

\section{Statement of the problem}

The environmental impact has becoming series problems in today's construction environments. What makes the construction projects delayed and makes cost overrun? The environmental impacts were serious factor which limit most of the construction parties. At the beginning it looks like a simple problems but after a time it begins to stack the overall construction processes. So the study focused on the impacts of environment on building construction projects in sodo town. The construction parties who are found in this town still raise these questions to the government. But the government would not give a response until the present time. So this factor becomes difficult issues especially in sodo town. This environmental problem makes the building construction projects delayed and cost overrun because they invest unwanted/unexpected expenses for unexpected adverse environmental factors. In fact most of the environmental problems arise due to environmental nature.

\section{Objectives of the Study}

- To identifying the cause of different Environmental Impact over building construction projects in woliatasodo town.

- To analyses the effect of different types of environmental impacts on building construction projects in woliata sodo Town.

- To understand the environmental impacts and its consequence on building construction projects in woliatasodo Town.

\section{LITERATURE REVIEW}

Environmental impact is the effect of a change in the physical environment. The impacts of environment over construction projects have becoming serious problems in today's construction world. Construction Environment is the most crucial things in order to construct a feasible physical structure. According to (Elis's Salleken, Environment and construction., 2003)there are many environmental impacts on any world's construction for instance: bad weather condition, soil character, material availability and its cost, fluctuable temperature, topography, access road, site boundaries are the most crucial factors in the construction worlds.

Environment is constantly changing. There is no denying that. However, as our environment changes, so does the need to become increasingly aware of the problems that surround it. With a massive influx of natural disasters, warming and cooling periods, different types of weather patterns and much more, people need to be aware of what types of environmental problems our planet is facing. Global warming has become an undisputed fact about our current livelihoods; our planet is warming up and we are definitely part of the problem.Current environmental problems make us vulnerable to disasters and tragedies, now and in the future. Current environmental problems require urgent attention. The following are the major current environmental problems: these are pollution, global warming, overpopulation, Natural Resource Depletion, Waste Disposal, climate change, Loss of Biodiversity, Deforestation, Ocean Acidification, Ozone Layer Depletion, Acid Rain and Water Pollution (Dixon, The Impacts of Construction and the Built Environment)., September 2010). This environmental impacts also become one main problems in different construction projects of Ethiopia. Those environmental factors have different impacts on the progress of every construction projects. 
The analysis of those environmental factors is based on their consequences on the progression of the construction projects. Since different activities have different environmental requirements, the extent of impact must be estimated for each environmental sensitive activity. It should be noted that estimation of impact anticipated delay upon individual construction activities is not presently requirement for construction contracts. Impacts are usually indicated in the special environmental factor clause as the monthly impact or delay for the project in general. The delays are not linked to specific activities, and the severe environmental factor criteria used to define an environmental resulted delay day is the same for all construction activities that occur on the project regardless of the activity's degree of sensitivity to those environmental factors (Alarcon. D.K., 1993). The number of anticipated environmental delay days in each month of the year is included in a special environmental factor clause within the project manual.

The analysis is based on the severe environmental factors of the activities thought to have been delayed. If the experienced environment was more severe than the base line estimate for the activities being evaluated, then the contractor may be granted a time extension. The part of the evaluation involves an analysis of the contractor's schedule to determine if work scheduled to be performed was actually delayed, and if such delay was on the "critical path," thereby delaying overall completion (Ncolis's Salleken, 2003).

\subsection{Environmental Impacts over building construction projects}

Environmental impact on construction project can be seen in different forms on a given construction project. The research studies and analysis the impact of main environmental factors that challenges construction projects that avail in the area. Those factors are: climatic and weather condition, soil characteristic of the area, availability and productivity of workman for a given construction project (Edam, 1998). Environmental assessment (EA) is the assessment of the environmental consequences (positive and negative) of a plan, policy, program, or actual projects prior to the decision to move forward with the proposed action.

In this context, the term "environmental impact assessment"(EIA) is usually used when applied to actual projects by individuals or companies and the term "strategic environmental assessment" (SEA) applies to policies, plans and programmed most often proposed by organs of state. Environmental assessments may be governed by rules of administrative procedure regarding public participation and documentation of decision making, and may be subject to judicial review. The purpose of the assessment is to ensure that decision makers consider the environmental impacts when deciding whether or not to proceed with a project. The International Association for Impact Assessment (IAIA) defines an environmental impact assessment as "the process of identifying, predicting, evaluating and mitigating the biophysical, social, and other relevant effects of development proposals prior to major decisions being taken and commitments made". EIAs are unique in that they do not require adherence to a predetermined environmental outcome, but rather they require decision makers to account for environmental values in their decisions and to justify those decisions in light of detailed environmental studies and public comments on the potential environmental impacts (Mackinnon, 2012). The Application of Science in Environmental Impact Assessment).

\subsection{Construction Site and the Environment}

Construction is a process that consists of building or assembling of infrastructure. Construction aims at making long live structures and buildings. In general, there are three types of construction i.e. building construction, heavy \& civil construction and industrial construction. Construction is also described as the utilization of cement, sand, aggregates, concrete, steel, plumbing, conduits, electrical fittings, wood work, painting, finishes etc. to make a dedicated structure which is utilized for some specificpurpose. Since past many decades, mankind is manipulating the natural environment to better suit its needs for providing accommodation for people, building industries, businesses and commercial centers, development of infrastructure and related amenities (roads, highways, electricity networks, playing areas, gymnasiums (Construction projects around the world have a significant impact on our environment, both on a local and a global scale. Every stage of the construction process has a measurable environmental impact. With a rapidly developingglobal economy, it is crucial that we understand how the construction projects we undertake impact the environmentand how we can measure and reduce that impact in the future (Nony, 2005). 


\subsection{Project Feasibility study}

The goal of each project is a beneficial change. Economic changes, the industrial revolution, the tremendous progress in using information and communications technologies all contributed to the Development of new project management ideas, techniques and methods. New product development is connected with uncertainty that includes both internal (e.g. communication in project team, planning techniques, and cash flow) and external environments (e.g. social, economic, political, technological conditions). Sources of uncertainty are wide ranging and have a fundamental effect on projects and project management .Uncertainty is an important issue in the support of any decision-making in the process of new product development. Since most companies should estimate project

/parameters, there is a need to develop an approach that takes into account the imprecise character of data and copes with enormous amount of data. Feasibility is the process of investigating a need, problem, and solutions in sufficient detail to determine if a solution is economically viable and worth developing. The feasibility process includes consideration of alternative solutions and the benefits and economic viability ofeach tasks (Nicholas, 1987).

The right direction of the project, recommendations for the most effective strategy and definition of the risks and achievable objectives emerge from the feasibility study. In this document we can find alternative solutions and their analysis or environmental impacts. As a part of compliance analysis, environmental consultants are employed to conduct surveys that determine pre- existing or potential environmental liabilities. An environmental site assessment is important, particularly in the field of construction development, as a lack of potential liability will eliminate the need for further assessments. Actual testing of soils, air and building materials will not occur unless a potential contamination is identified. Purchase of property, buyouts, applying for a loan based on property as capital asset and applications for land use permits usually require some type of environmental assessment.

\section{The Role of Stockholders on impacts of environment on construction projects}

\subsection{The Client}

The construction client is responsible for interpreting and translating the core activities' goals and value creation to create good working conditions in our buildings and premises. This includes working environment design with a good understanding of the organization's activities in combination with changes in technology, working conditions and building production organization. A success factor is considered to be the ability to transform future company requirements into the built environment requirements at the strategic, tactical and operational level. Already The Structure of Scientific Revolutions states that technology is socially formed and shaping.

\subsection{The Contractor}

Environmental contractors are usually hired after a building or land area has been deemed unusable or unsafe due to chemical or biological contamination. They perform required restoration or cleanup activities to make the area safe or suitable for use. These contractors may be involved with emergency response teams when natural disasters introduce debris or other contaminants that put the public in danger into the environment (Jhony, 3rd Edition, 2010)Environmental contractors also participate in sustainable building projects, including using environmentallyfriendly materials and processes to restore existing structures. These practices promote recycling and prevent erosion control. Environmentally-friendly practices also help conserve energy and other natural resources. They also reduce air and water pollution.

Environmental contractors are often responsible for assessing the condition of a contaminated site and determining the actions required to make it safe for use. These assessments may include recommending the removal of hazardous waste, asbestos, and mold. Contractors may oversee the cleanup of infectious, biohazard, chemical, or sewage contaminants. They also might be involved in Brownfield and Superfund site restoration. Like environmental engineers, environmental contractors provide clients with solutions to their contamination problems once contamination has occurred. However, the contractor might also advise clients on how to prevent environmental hazards. Contractors should have detailed knowledge of the regulations established by government organizations such as the U.S. Environmental Protection Agency (EPA) and the U.S. Occupational Safety and Health Administration (OSHA).They might also recommend ways to restore or renovate infrastructural systems to reduce the system's negative effects on the environment. (Glossary of Career Education Programs Engineering Job Description of an Environmental Ang, 2008). 


\subsection{The Consultant}

The role of environmental consultants in building projects is both fundamental and essential, especially when dealing with a site that may be potentially contaminated. Environmental consultancy is a means of providing advice and strategies that ensure engineers, architects and construction companies working on the building project meet all compliance regulations and also protect the safety of their workers as well as keep the clients liability minimized. A common function of an environmental consultant is to provide site assessments that analyze the means of meeting regulations in everything from waste management. As such, environmental consultants often specialize in a particular field. They are not simply environmentalists there to advise on sustainability, but also provide surveys of foundation design and the geology of a site, determining things like slope stability and flood risk.

\section{Types of Environmental impacts That Affect the Construction Environment}

\subsection{Project Location}

The exact location of the project highly affects the construction processes. That means if the construction is comfort to moving and constructing it better to facilitate the tasks but the reverse is not true. In geographical terms, construction and material costs, land costs and design standards vary widely across all the environment because of the varying distances from suppliers, climate and weather conditions, and general market conditions. Even within a country, variations would exist depending on whether a project is being implemented in a peripheral or central area, or in an urban or rural context. Generally, the more remote a project is, the more expensive it would be because of the cost of transporting construction materials and equipment to the site. In an urban location, land costs are usually much higher (Earthscan, 2002).

\subsection{Effects of climate change on building construction Projects}

Climate is defined as the statistical average (mean and variability) of weather conditions over a substantial period of time, accounting for the variability of weather during that period. The relevant parameters used to characterize climate are most often surface variables such as temperature, precipitation, and wind, among others. The effects of climate change on the Project are not considered to be particularly relevant during the construction phase due to the time frame associated with climate change relative to the proposed time frame for Project construction. During Project operation, the changes noted above are expected to have an effect.

\subsection{Severe Weather Condition}

Refers to any dangerous meteorological phenomena with the potential to cause damage, serious social disruption, or loss of human life. Weather conditions severely affect all rigging operations. Industries such as, construction and others that involve outdoor construction thoroughly need to consider weather conditions while planning and executing their operations. Heavy wind, dust or fog can cause serious injuries to the workers and also heavily damage rigging hardware. Weather conditions affect the stability, design and performance of the structure. The construction industry needs to make note of such conditions as most of its Operations are performed in the open and subject to all kinds of weather. This means there is a far bigger risk involved for the rigging equipment and the workers using it. The following are the main severe weather conditions that mainly affect all construction sites and its workers

\subsection{Cold weather}

Cold weather can affect construction adversely. Perhaps the most critical factor in construction operations carried out in cold weather is ensuring that mortar and grout get adequate heat for normal cement hydration. Lower temperatures either completely stop or slow down the process of cement hydration due to lack of heat, which reduces the masonry's bond strength. Frozen masonry units must be melted and dried before use. It is important to protect mortar from freezing temperatures. A frozen mortar mill significantly reduces the compressive strength, the bond strength and also decreases the water penetration resistance of masonry . 


\subsection{Hot and Dry Weather}

Hot and dry conditions can also pose major problems for the construction industry. The primary concern in hot weather condition is rapid evaporation and absorption of water from mortar. Lack of moisture can have dramatic effect on the building materials. It is important to keep masonry units away from direct sunlight in cool shaded places. High temperatures may cause the mortar to settle prematurely. A premature mortar will not have enough water content for the brick lay to hold onto. This will decrease the overall bond strength between the brick and the mortar which may cause leaks in the structure. Sprinkle some water on the bricks before laying them. Due to the hot weather, bricks rapidly absorb water and lose moisture (Earthscan, 2002).This in turn makes them absorb water from the mortar mixture which will decrease the bond strength to a great extent. Dry weather means lack of moisture, which may also cause formation of dry dust. Large amounts of dust clouds hovering around the construction site can be dangerous.Dust also generates dirt which can cause unnecessary complications in the machinery and also risk the health and safety of the workers. Many equipment and machinery used on site have filters, which need to be cleaned and fixed with properly on regular basis. Dirt and dust can enter working parts and cause breakdowns. It is important that all equipment and machinery are cleaned and lubricated regularly (Albert, 2010)

\section{Impacts of Environment on Construction Resources}

\subsection{Impacts of environment on labor productivity}

It is axiomatic that the construction industry has a significant role to play in the economic growth of a nation.

The industry employs a large number of skilled, semi-skilled and unskilled workers and its activities provide work for the economic sector. The success or failure of the construction sector can therefore seriously influence the living standards of the population. Site productivity is one of the most difficult factors to measure because its determinants can vary significantly depending on size of site and place of measurement. The definition of Productivity ranges from industry-wide economic parameters to the measurement of crews and individuals. For instance, Single-Factor productivity measures such as Average Labor Productivity (ALP) looks at the impact of one factor input (labor), whereas total (Multi- Factor) productivity measures take into account the impact of all inputs and output (Crawford, 1997).

\subsection{Impacts of environment on construction materials}

In fact the location and topography and other difficult air condition are highly affect the construction environment and construction materials. That means the construction material is highly affected by the condition of the environment. The following are some of the factor which affects the construction materials:-

\section{$>\quad$ Termite}

The acidity of the soil

Heavy rainy

The harsh sun Dust

Storing area etc. is affect the construction material quality, durability, strength and other properties of the material will be changed. Not only this but also the manufacture, transport, and installation of a building materials are affected by the location of the construction site and the source of the material. Such as steel and concrete require a large quantity of energy, despite them representing a minimal part of the ultimate cost in the building as a whole (Mackinnon, 2012)

\subsection{Impacts of environment on construction equipment's}

Construction organizations are responsible for the designing, planning, execution, operation and maintenance of housing. buildings, highways, airports, docks, harbor, irrigation systems, essential municipal services, structural work bridges, tunnels, dams, reservoirs, power stations etc. These construction projects are usually classified in to residential, commercial, industrial and heavy works. All these projects required different types of equipment and machinery and have their own level of usage. For example residential projects have a light level of equipment use. It requires simple and traditional machines like fork-lifters, backhoe, hauling and hoisting equipment, material handling along with pneumatic tools. Commercial projects have moderate use of equipment and machinery. Industrial and heavy construction projects required intense and high utilization of machinery for carrying out mass excavation, stabilizing, compacting, asphalt paving and finishing, pipelines, railroads and many other special activities. During project execution, the external environment has impacts onsite mechanized construction activities. Even a minor impact, such as a small release or spill of a hazardous substance, can cause a health or environmental threat and lead to costly cleanup activities. Therefore, there is need for identification and prioritization of hazardous impacts that assists contractors for addressing them in a prompt manner. Hence, this study aims to determine environmental concerns that emerge due to the usage of heavy construction equipment and machinery (Slavish, 2013). 


\section{METHODOLOGY}

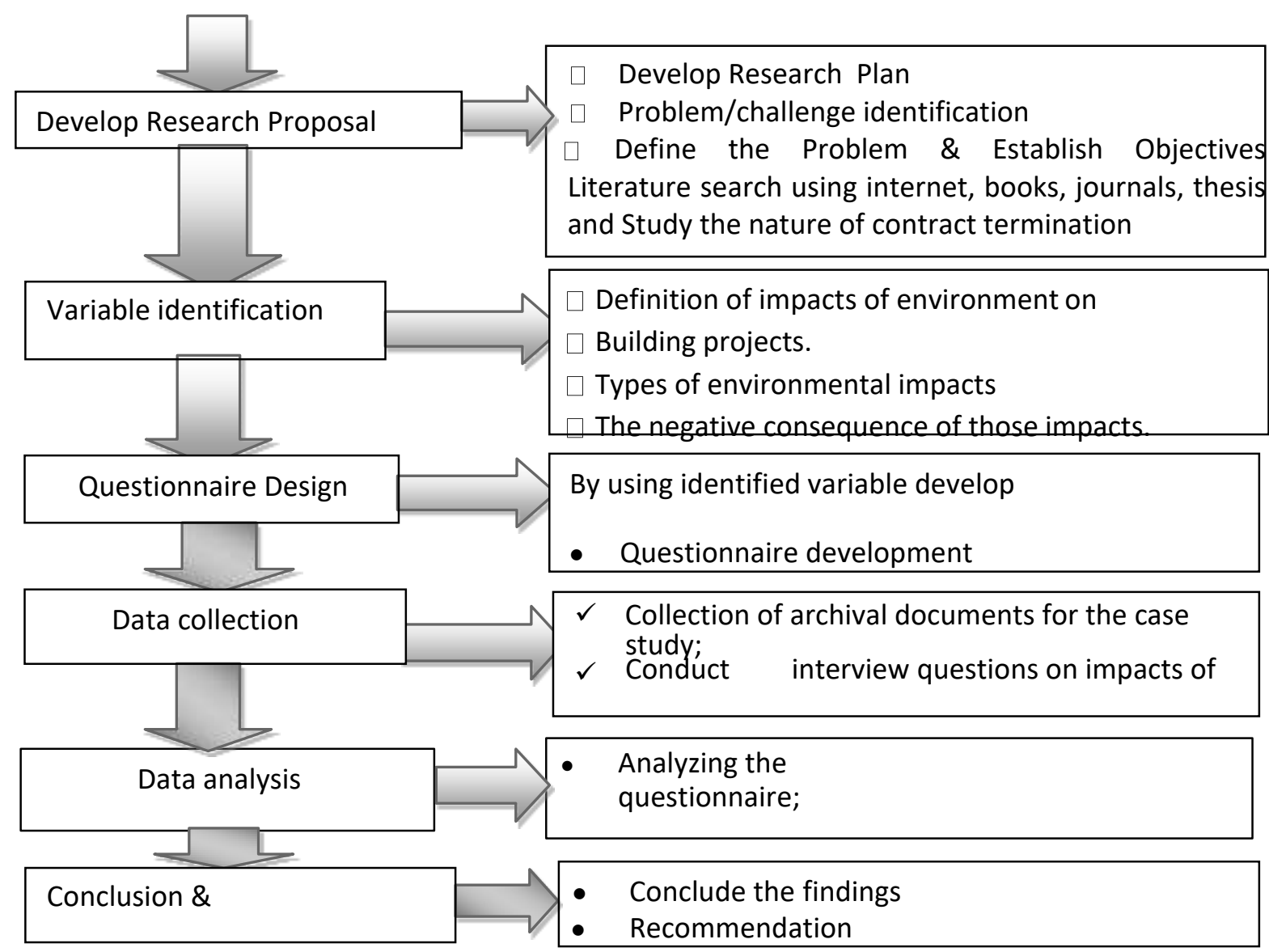

\subsection{Sampling techniques}

I have been used different techniques to select the sample of construction firms. But experience analyses is the most important parameters used to select the following most interesting company. In addition I have been used this formula in order to determine the specific quantities of the respondent numbers.

By using ( (Yamane, 1967)

\section{Equation 1 sampling techniques Yamane formula}

\section{$\mathrm{A}=\mathrm{X} / 1+\mathrm{X}(\mathrm{e} 2)$}

Where $\mathrm{A}=$ Number of selected company, $\mathrm{X}=$ number of sample, e=adjusting factors. Expected Sample size $(\mathrm{x})=16$ then, $A=16 / 1+16\left(0.05^{2}\right)=15.4=15$ according to this

formula I have been distributed 15 questioners. But 11 questioners gained from the respondent. The remaining questionaries' were not come again because of different reasons for example most of the respondent parties were not present on the office. And they were very busy and they have not enough time to fill the questioners. Samples of construction sectors that we have been conducted (distributed) our research questioners are stated in the following

\subsection{Data Analysis Methods}

Following formula; 1 -not affect $=0$,

2-Less frequentlyaffect $=25$,

3 - Frequently affect $=50$,

4- Very frequently affect $=75$ and

5 -Extremly frequently affect $=100 \%$.

Equation 2 happening (affecting) calculation

$\mathrm{M}(\%$ of Happening $)=\sum(5 \mathrm{n} 5+4 \mathrm{n} 4+3 \mathrm{n} 3+2 \mathrm{n} 2+1 \mathrm{n} 1) * 100 / 5(\mathrm{~N}) \quad$ Equation 3.2

$\mathrm{M}=\%$ of Happening (affecting), $\mathrm{n}=$ Number of responding on each question and $\mathrm{N}=$ Total number of respondent. 
Table 1: Environmental factors

\begin{tabular}{|l|l|l|l|l|l|l|}
\hline \multirow{2}{*}{$\begin{array}{l}\text { No } \\
1\end{array}$} & Environmental factors & 1 & 2 & 3 & 4 & 5 \\
\cline { 2 - 7 } & $\begin{array}{l}\text { Challenges due to severe weather conditions in the } \\
\text { areas }\end{array}$ & 4 & 3 & 1 & 1 & 1 \\
\hline
\end{tabular}

M (\% of Happening $)=\sum(5 \mathrm{n} 5+4 \mathrm{n} 4+3 \mathrm{n} 3+2 \mathrm{n} 2+1 \mathrm{n} 1) * 100 / 5(\mathrm{~N})$

$\mathrm{M}=\sum(5 * 1+4 * 1+3 * 1+2 * 3+1 * 4) * 100 / 5 * 11=2200 / 55=40 \%$

\section{RESULTS AND DISCUSSIONS}

Table 2: Environmental challenges due to natural conditions of the area

\begin{tabular}{|l|l|l|l|}
\hline \multirow{2}{*}{$\begin{array}{l}\text { A } \\
\text { A }\end{array}$} & Environmental factors & $\%$ ge & Rank \\
\cline { 2 - 4 } & Environmental challenges due to natural conditions of the area & & \\
\hline 1 & Challenges due to geographical condition/location of the area. & 38.18 & 5 \\
\hline 2 & Challenges due to severe weather conditions in the areas. & 40 & 4 \\
\hline 3 & Challenges of climate condition over construction project & 46.6 & 2 \\
\hline 4 & The properties of the Soil in the construction environment. & 45.45 & 3 \\
\hline 5 & Availability of construction materials around the area. & 61.81 & 1 \\
\hline
\end{tabular}

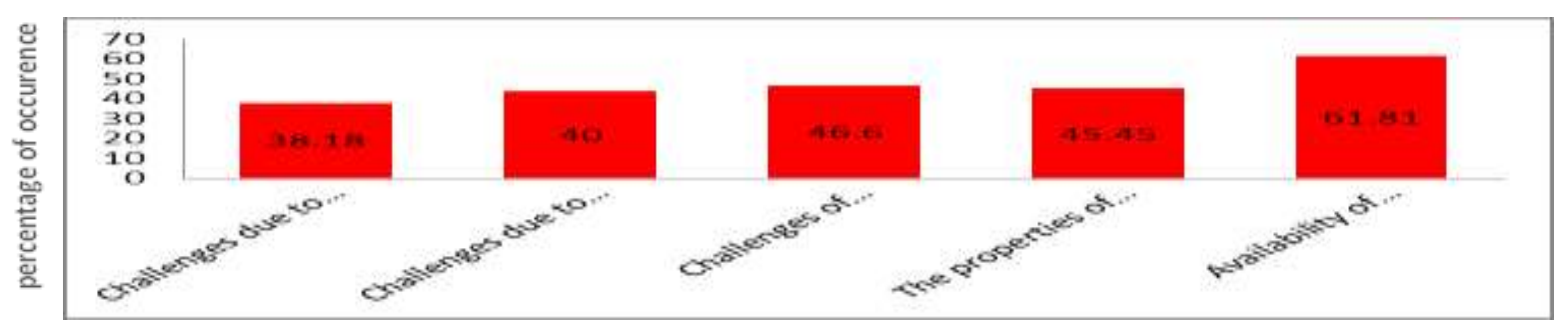

Figure 1:Impact of environment on construction resources

Table 3: Impact of environment on construction resources

\begin{tabular}{|l|l|l|l|}
\hline B & Impact of environment on construction resources & $\%$ Age & Rank \\
\hline 1 & The impacts of environment on labor productivity. & 56.36 & 3 \\
\hline 2 & The impacts of environment on construction materials. & 54 & 4 \\
\hline 3 & The impacts of environment on construction equipment. & 61.81 & 2 \\
\hline 4 & The waste disposal management system in the site & 70.9 & 1 \\
\hline
\end{tabular}

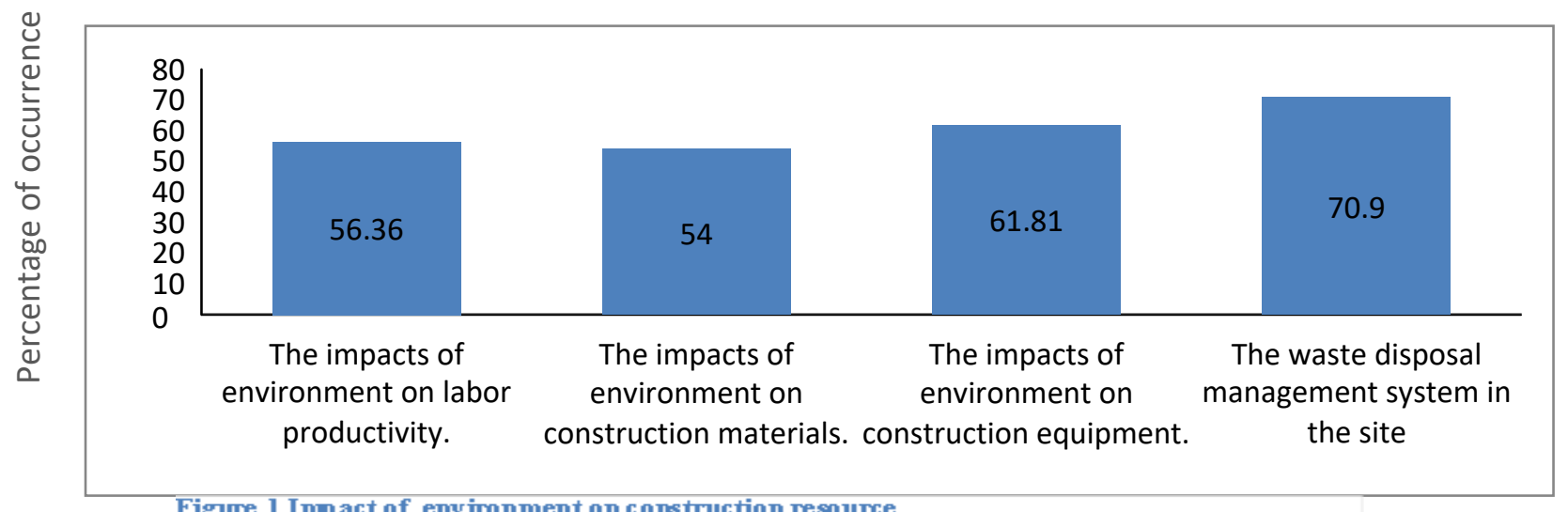

Figure 1 Imp act of environment on construction resource

Figure 2: Impacts of the environments on Social, economic, political aspects in the area 
Table 4: Impacts of the environments on Social, economic, political aspects in the area

\begin{tabular}{|c|c|c|c|}
\hline $\mathrm{C}$ & Impacts of the environments on Social, economic, political aspects in the area & \%age & Ran \\
\hline 1 & The impacts of environment on social aspects in the area. & 46 & 3 \\
\hline 2 & The impacts of environment on economic aspects in the area. & 56.36 & 1 \\
\hline 3 & The impacts of environment on political aspects in the area. & 49.09 & 2 \\
\hline
\end{tabular}

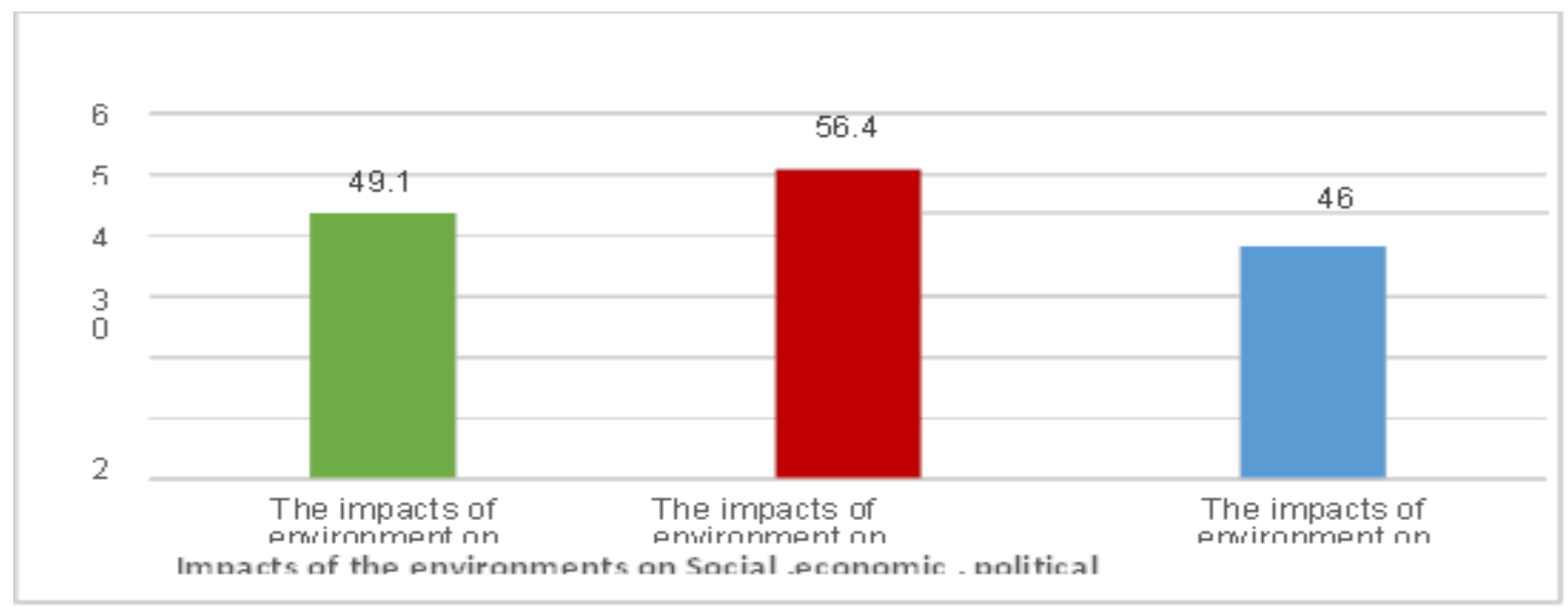

Figure 4: Market condition of the environment

\section{Table 5: Market condition of the environment}

\begin{tabular}{|l|l|l|l|}
\hline D & Market condition of the environment & \%age & Rank \\
\hline 1 & The amount of wage and salary of labors in the area. & 47.27 & 5 \\
\hline 2 & The cost of construction equipment in the area. & 82.5 & 1 \\
\hline 3 & The unsuitability of the environment for building construction. & 50.91 & 4 \\
\hline 4 & The attractiveness of the area to initiate stakeholders to build on it. & 66 & 3 \\
\hline 5 & Increase of material price at the area & 72.72 & 2 \\
\hline
\end{tabular}

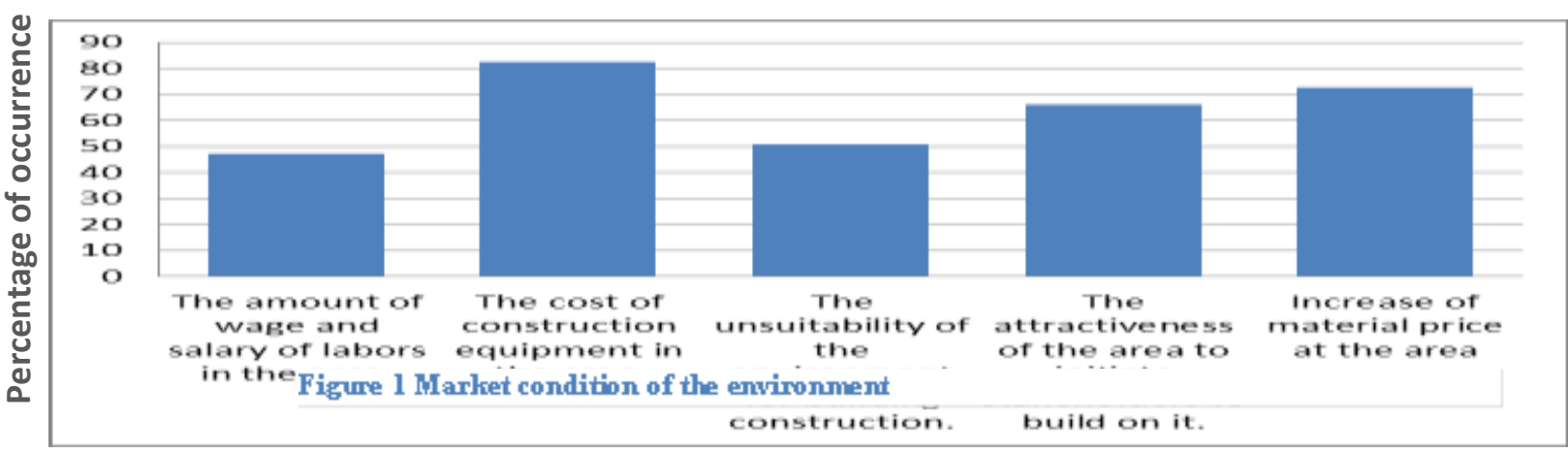

Figure 5: Impact of the environment on construction productivity 
Table 6: Impact of the environment on construction productivity

\begin{tabular}{|l|l|l|l|}
\hline E & Impact of the environment on construction productivity & $\%$ age & Rank \\
\hline 1 & Availability of sufficient daily labor to execute work. & 30.90 & 4 \\
\hline 3 & Availability of site experienced laborers to facilitate the work. & 76.36 & 1 \\
\hline 4 & The degree of construction processes in the area. & 58.18 & 3 \\
\hline
\end{tabular}

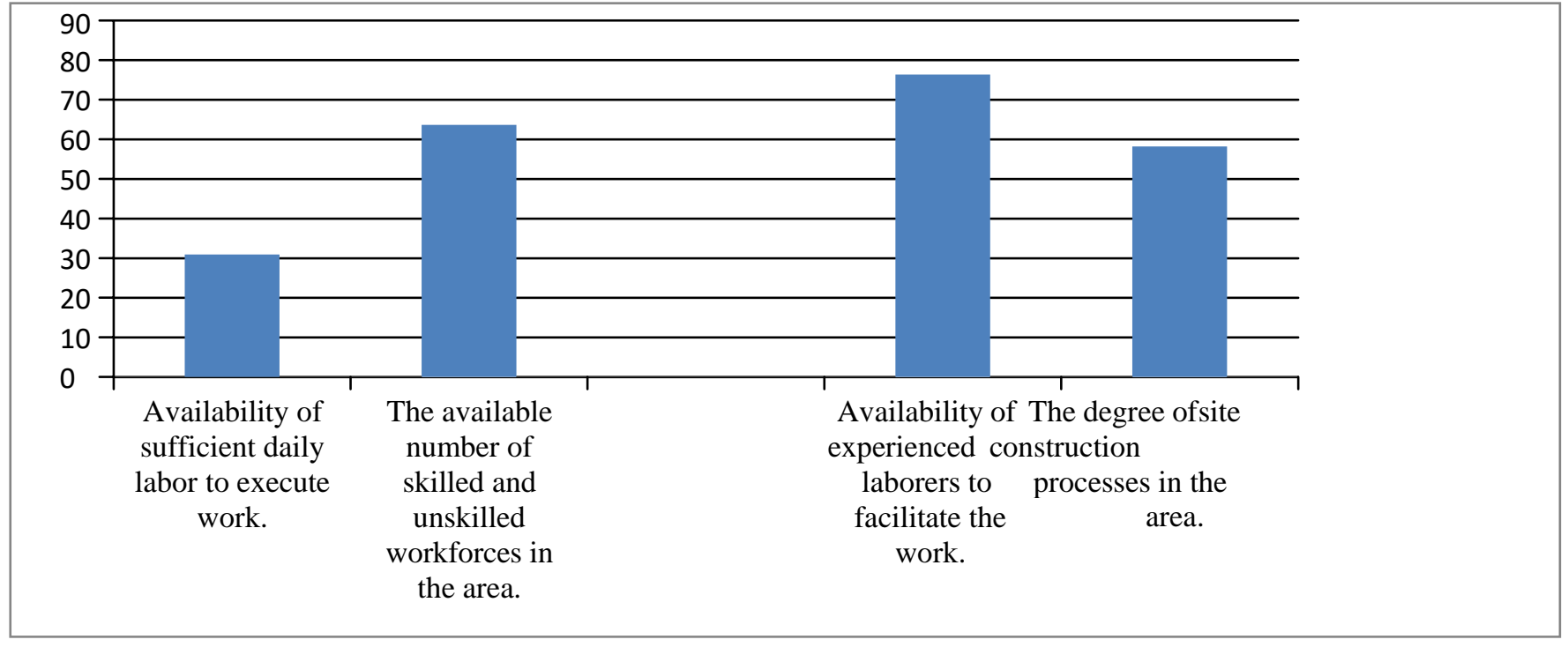

Figure 6: Impact of the environment on construction productivity

Table 7: The availability of the construction stockholders around the area

\begin{tabular}{|l|l|l|l|}
\hline F & $\begin{array}{l}\text { The availability of the construction stockholders of the area due to } \\
\text { Impact of environment. }\end{array}$ & Rank \\
\hline 1 & $\begin{array}{l}\text { The Involvement of construction party at the area to construct different } \\
\text { Construction projects. }\end{array}$ & 60 & 4 \\
\hline 2 & The construction parties communicate to each other. & 66 & 8 \\
\hline 3 & The applicability of dispute resolution methods in the area. & 49.1 & 10 \\
\hline
\end{tabular}




\section{Conclusion}

In this finding I were organized different types of environmental impacts over the building construction projects. For instance: geographical condition of the environment, the severe weather condition, the climatic change, availability of skilled and unskilled labors around the area, the price and availability of different building construction resources, the involvement of different construction groups in to the area were some of the environmental factors around this area. After made a detail investigation we have got the following top series environmental problems with their percentage of affecting (occurrences) around the area. Those factors are: Increase of material price at the area (67.27\%), Availability of construction materials around the area $(63.64 \%)$,

The Involvement of construction party at the area to construct different construction projects (60\%), the available number of skilled and unskilled workforces in the area $(60 \%)$ and Challenges of climate condition over construction project (58.18\%). Many contractors found in this area may fall over different environmental challenges. And their final consequences on the implementation of the construction project in this town resulting construction delay, interruption of project and cost risks. So to overcome these problems, are some requirements expected from different parties. Also it deals with requirements expected from contractors, consultants, owners, and government.

\section{REFERENCES}

[1] Alarcon. D.K., (1993). Environmental Issues: The Response of Industry and Public Authorities.

[2] Albert. (2010). Environmental Impact Assessment, Emran, third edition, 2004. Environmental engineering.

[3] Dr.A.Paulmakesh, e.tl., Oct 2021, Implementation of project management for strategy realization, Journal of University of shanghai for science and technology, Vol 23, issue 10, 887-897

[4] Al-hammed, A. (1997). Environmental impacts, Alarcon, L. 1994. Construction and environment.

[5] Christiano. (1987). Development of construction contractor's performance measurement framework.Crawford, B. C. (1997). Handbook of Sustainable Building, James and James:. London.

[6] Dixon. (September 2001). The Impacts of Construction and the Built Environment.

[7] Dixon. (September 2010). The Impacts of Construction and the Built Environment).

[8] Earthscan. ( 2002). Environmental Impact Assessment (Second Edition), . McGraw-Hill Inc.Edam, J. 2. (1998). The Environment: Principles and Applications, ,. London.: Routledge.

[9] Dr.A.Paulmakesh, e.tl., April 2021, Management of Contracts for durable concrete structures, Innovations, number 64, pg.no 1044-1054.

[10] Dr.A.Paulmakesh, e.tl., Dec 2021, Analysis of uncertainty in a construction project, YMER, Vol 20, Issue 12, pg.no 324-332. 
[11] Elis's Salleken, f. e. (2003). Environment and construction.

[12] Nony. (2005). Cone.struction and its environment, Nonnie, N. 2005. Environmental impacts.

[13] Slavish, M. (2013). Environmental Issues in Construction: Special Report 94. London, CIRIA.Yamane. (1967). sampling techiques formula . 